\title{
DEVELOPMENT OF SEXUAL AND VEGETATIVE : ORGANS ON DETACHED FOREST TREE BRANCHES CULTURED IN THE GREENHOUSE ${ }^{1}$
}

\section{INTRODUCTION}

In 1924 when Stout, McKee, and Schreiner commenced, in Populus, the first comprehensive hybridization work within a forest tree genus, it was necessary to climb high into large trees or to work on roof tops in order to effect interspecific cross pollination. (6). In 1935 von Wettstein-Westersheim (7) published details of a technique by which flower-bearing branches cut from male and female poplars of the desired species were cultured in the greenhouse through stages necessary for cross pollination to seed maturity on the part of the maternal parent. The culture solution was tap water. The following year Al"benskii and Delitsina (1) reported successful results in Populus using a similar technique, but with Knopp's solution as the culture medium. When interspecific hybridization in Populus was undertaken on a comprehensive scale by the author in 1938 it soon became apparent that there was a need for greater knowledge of some of the phenomena. relating to the "detached branch" method of hybridization. The information sought included especially the following:

1. A means of increasing the efficiency of the method in terms of final yield of mature seed, which was very low (even in intraspecific crossing) in a number of species, notably $P$. grandidentata and $P$. tremuloides. The logical approach was considered to be (a) augmentation of stored nutrients of the branch by nutrient culture solutions; and (b) the provision of optimum light, temperature and humidity conditions for the developing flowers and seeds. 


$$
\text { CULTURES - JOHNSON }
$$

2. An indication of the earliest time during winter dormancy at which proper development could be obtained in detached branches, in order that the greenhouse crossing season could be extended to a maximum. In designing studies on this problem it was considered worthwhile to include a wide range of forest tree materials to determine: (a) which species could be carried to the length of maturing seed in the greenhouse, i.e., would be adaptable to the method; and (b) which species would produce viable pollen on detached branches, and at what time during the dormancy period.

3. The compilation of a phenological calendar for the species being used in the hybridization program, especially in Populus, which would show the period of time required under greenhouse conditions to produce pollen or stigmatic receptivity by flowering branches of different species collected at different times during the dormant period.

The present paper reports the results of the studies undertaken to obtain information on the problems stated above.

\section{General Methods}

The procedures used in obtaining deliberately imposed experimental conditions are described in the pertinent sections following. But it is useful here to describe the standard procedure generally followed in the practical breed. ing work-almost entirely in Populus--which forms the basis upon which experimental conditions were built.

Flower-bud branches were cut from the trees, usually as large branches, brought immediately to the greenhouse, trimmed to smaller, straighter branches usually two to three feet long, and placed in groups of three or four in twoquart jars filled with tap water-the jars being flushed every few days by water pressure from a hose. This procedure was standard for all experiments, except for obvious departures in the culture solution and size-of-branch experiments in Sections 1 and 3 respectively.

During the first four winters of greenhouse hybridization, temperatures were maintained at either $60^{\circ}$ or $70^{\circ} \mathrm{F}$. (the lower proving the better), relative humidity was held at approximately $50 \%$ through the agency of moist peat on the floor, and illumination was by natural sunlight augmented on dull days by electric lighting. This procedure was standard until it was superseded in November, 1941, by that outlined in Section 3 following.

In all cases of electric lighting, one 500 watt bulb under a parabolic reflector was suspended four feet above each square yard of bench space.

\section{EXPERIMENTAL}

\section{THE EFFECT OF NUTRIENT SOLUTIONS ON SEED PRODUCTION IN} Populus grandidentata

Branches having numerous flower buds were cut from a single female tree of $P$. grandidentata on 21 February, 1940, brought to the greenhouse and distributed as uniformly as possible among 282 -quart pars containing seven nutrient solutions (considering distilled water as such) arranged in a fourreplicate randomized series. 
The nutrient solutions are given in Table 1. Hoagland's, solution was made up according to the procedure given by Eaton (2) in which iron, boron, manganese, zinc and sodium chloride are added to the base nutrient solution. The peat-humus infusion was made by mixing $1.25 \%$ (by weight) air-dry sedge peat with distilled water. Chemical analyses of the sedge peat have been reported by Farrar and Grace (3). The $\mathrm{pH}$ of the infusion was 5.6. Distilled water was used in making up and maintaining levels in all solutions. All solutions were renewed on 14 March.

As female flowers became receptive they were fertilized with viable pollen of the same species. The greenhouse was accurately controlled at $60^{\circ} \mathrm{F}$. and maintained at about $50 \%$ relative humidity. The experiment was terminated on 30 March.

In tabulating results on relative seed set it was found convenient to use a seed capsule index, which took into account the original number of catkins, the number of capsule-bearing catkins, and the average number of capsules per catkin which actually bore seed. It gives approximately the proportion of seeds obtained from the material cultured in each solution. The results are presented in Table 1 .

It was concluded that distilled water is definitely better as a culture medium than any of the other solutions tested, and that the data do not afford any obvious leads to further studies.

Table 1. Effect of culture solutions on the development of catkins and seed capsules on detached branches of

\begin{tabular}{|c|c|c|c|c|}
\hline Culture Solution & $\begin{array}{l}\text { Total No. } \\
\text { of catkins }\end{array}$ & $\begin{array}{l}\text { Percentage } \\
\text { of catkins } \\
\text { elongating }\end{array}$ & $\begin{array}{l}\text { No. of } \\
\text { replicates } \\
\text { (out of 4) } \\
\text { producing seed } \\
\text { capsules }\end{array}$ & $\begin{array}{l}\text { Seed } \\
\text { capsule } \\
\text { index }\end{array}$ \\
\hline Distilled water & 345 & 96.5 & 4 & 171 \\
\hline 1/10 Hoagland's $(\mathrm{H} / 10)$ & 320 & 79.4 & 1 & 12 \\
\hline Hoaglands $(\mathrm{H})$ & 420 & 93.6 & 1 & 12 \\
\hline $1.0 \%$ sucrose $(\mathrm{S})$ & 358 & 88.3 & 3 & 36 \\
\hline $\mathrm{H} / 10+1.0 \% \mathrm{~S}$ & 373 & 95.4 & 2 & 32 \\
\hline $1.0 \% \mathrm{~S}$ & 331 & 81.0 & 0 & 0 \\
\hline Peat-humus infusion & 362 & 81.2 & 1 & 0 \\
\hline
\end{tabular}

${ }^{1}$ Total number of catkins was determined by the chance occurrences of flower buds on the selected branches, and was in no way influenced by culture solutions.

2. The Effect of "Natural" Diurnal Variation in Light, TEMPERATURE AND Humidity

The failure to demonstrate beneficial effects from nutrient solutions led to a new attack on the problem of nutrition in detached flower branches, 
the governing principle being the provision of optimun environmental conditions for flower and seed development in order that the most efficient use might be made of the nutrients already stored in the branch. The criterion used as a guide to these optimum conditions was the normal outdoor conditions prevailing during the flowering and seed-setting period for Populus spp. (roughly, the month of May).

The temperature in the greenhouse (equipped with the Taylor temperature control system) was uniformly varied between $50^{\circ} \mathrm{F}$., at midnight, and $70^{\circ} \mathrm{F}$., at noon. The control was very close except occasionally where bright, warm mid-day sunshine gave temperatures up to $80^{\circ} \mathrm{F}$.

The lights were automatically switched on during the hours just before sunrise providing the necessary addition to natural sunlight to give 15 hours of continuous illumination-approximately equal to the length of day during May in this latitude.

Moist peat on and under the benches gave an average rclative humidity of about $60 \%$, simulating with perhaps some exaggeration the humidity conditions of the forest in May.

This procedure has been used since November, 1941, and has, it is felt, largely overcome the more serious difficulties which attended greenhouse culture of detached flower branches from female trees of certain Populus species.

\section{General Observation on Detached Branches of Populus IN THE GREENHOUSE}

During the course of the greenhouse hybridization work, differences in productivity of different types of branches, otherwise similarly treated, were noted systematically. The following points may be taken as reasonably established facts:

1. Large female branches, three to five feet long, generally were able to sustain a higher proportion of catkins to seed maturity than smaller branches, which tended to drop developing catkins prematurely.

2. Small male branches, about two feet long, produced pollen more quickly than larger branches.

3. Branches with bright, living bark were superior to those with dull scurfy bark in sustaining developing seed capsules to seed maturity. Heimburger has suggested (4) the use of branches from young trees.

\section{True and Imposed Dormancy in Forest Trees}

A study was undertaken to determine the time at which trees of different species pass from a state of true dormancy to one of imposed dormancy, the latter being a state in which the tree is no longer truly dormant but where growth cannot start because of unfavourable environmental conditions (5). The experiment involved semi-monthly collections of branches bearing flower and leaf buds and of cutting wood (current season's growth) from 17 species of forest trees. The detached branches were cultured as outlined in Section 2 above. Results are given in Table 2.

For most of the species studied it would appear that the transition from 
true to imposed dormancy occurred between the middle of November and the first of December. It is also apparent, from the calculations made on the difference in the time required for a given organ to develop in material collected at the beginning of imposed dormancy and in material collected one month later, that some form of sexual and vegetative development occurs soon after the breaking of true dormancy.

The usefulness in greenhouse hybridization of the data compiled in Table 2 is quite obvious (see Introduction). These data may also prove useful in indicating critical stages bearing on vegetative propagation experiments.

5. Phenological Observations on Detached Branches of

Forest Trees in the Greenhouse.

During six "greenhouse seasons" records have been kept on the length of time required by detached branches of various species to produce mature Howers (determined by pollen dehiscence in the male, and by apparently receptive stigmas in the female). It was found that species within a genus varied considerably in the time required; and that in all species (Populus acuminata somewhat of an exception) the time decreased as the materials were collected successively later in the winter.

A consolidation of these records is presented in Table 3 .

An outstanding feature of the data in Table 3 is the relatively constant rate of decrease in time to flowering as the collection date is advanced toward spring. Results of the preceding experiment (see Table 2) show that this decrease starts with the breaking of true dormancy and, as may be judged from Table 3, continues throughout the period of imposed dormancy. These facts indicate that a slow but constant development occurs in the flower buds during the period of imposed dormancy, which for most species extends onwards from mid-November or early December (see Table 2 ).

The data in Table 3 have been used extensively in planning the time schedules underlying control of coincidental flowering in the opposite sexes of different species used in greenhouse hybridization.

ACKNOWLEDGMENTS

The author is indebted to Dr. C. Heimburger and Messrs. H. W. Holtz and $\mathbb{E}$. C. Bradley for valuable assistance in carrying out these studies.

\section{REFERENCES}

1. Al'benski, A. V. and Delitsina, A. V., Experiments and investigations All-Union Inst. For. Cult. and For. Melioration, Moscow, 2nd Issue: 107-119. 1934 (Plant Breed. Abst. 5: 62. 1934).

2. Eaton, Frank M., J. Agric. Research 53: 433-444. 1936.

3. Farrar, J. L. and Grace, N.H. Can. J. Research, C, 19: 391-399. 1941.

4. Heimburger, C., Forestry Chron., 16:149-160. 1940.

5. Howard, W. L. Mo. Sta. Research Bull. 1. 1910.

6. Stout, A. B., McKee, Ralph H. and Schreiner, E. J., N.Y. Bot. Gard. 28 : 49-63. 1927.

7. Wettstein-Westersheim, W. von Z. Zuchtung A 18: 597-626. 1933. Plant Breed Abst. 4: 163-164. 1934. 


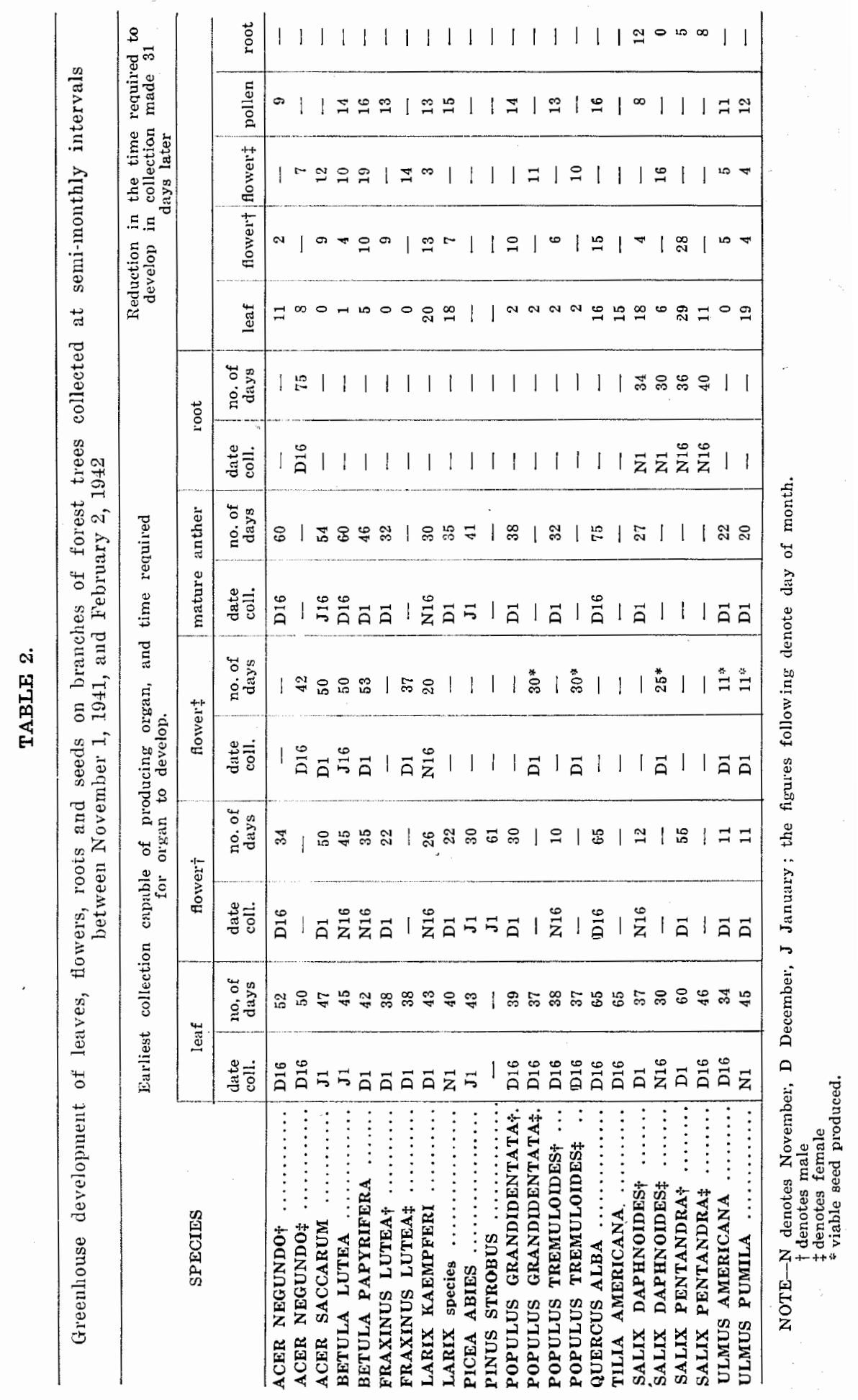




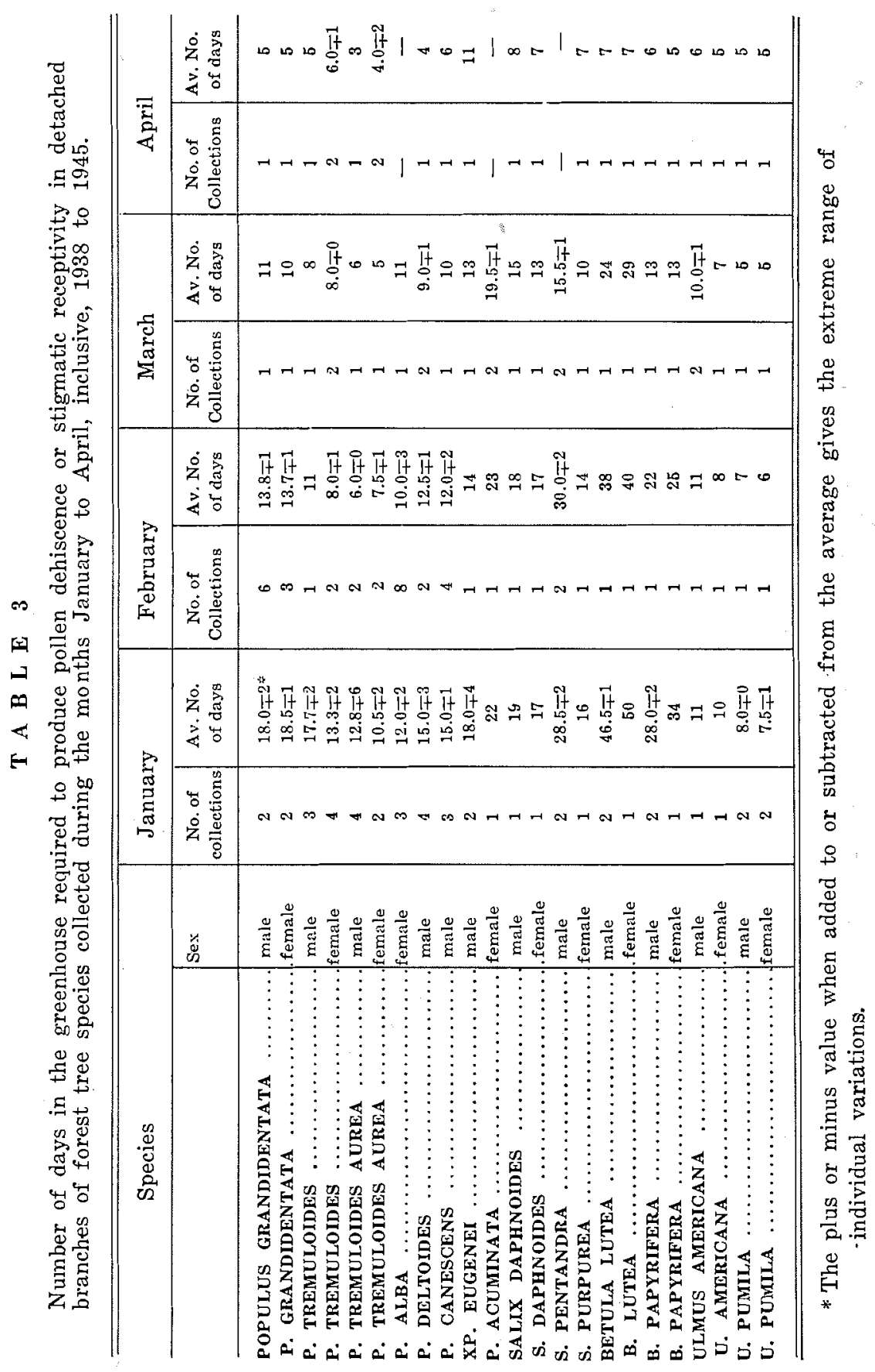

